\title{
Linking results of key and supplementary comparisons of regional metrology organization for electrical power
}

\author{
Oleh Velychko^ and Stanislav Karpenko \\ State Enterprise "Ukrmetrteststandard", Kyiv, Ukraine
}

Received: 5 January 2016 / Accepted: 3 May 2016

\begin{abstract}
A regional key comparison EURAMET.EM-K5.1 and a supplementary comparison COOMET. EM-S2 for electrical power were conducted between participating laboratories from the Eurasian region. Measurements were made over the period 2003 to 2011. The results showed good agreement between all but one of the participating laboratories. The proposed procedure of linking results of key and supplementary comparisons of regional metrology organization for electrical power is presented. Linking results is realized for EURAMET.EM-K5.1 key comparison and COOMET.EM-S2 supplementary comparison.
\end{abstract}

Keywords: Comparison, key comparison, supplementary comparison, linking, regional metrological organization, degrees of equivalence

\section{Introduction}

Mutual recognition arrangement (MRA) of international committee for weights and measures (CIPM) for national measurement standards and for calibration and measurement certificates issued by national metrology institutes (NMIs) is a response to a growing need for an open, transparent and comprehensive scheme to give users reliable quantitative information on the comparability of national metrology services and to provide the technical basis for wider agreements negotiated for international trade, commerce and regulatory affairs.

A regional metrology organization (RMO) key comparison $(\mathrm{KC})$ is $\mathrm{KC}$ executed in the framework of a RMO. The link to the $\mathrm{KC}$ reference value (RV) for a $\mathrm{KC}$ carried out by a RMO is obtained by reference to the results from those NMIs which taken part in the CIPM KC also. The degree of equivalence relative to the KC RV of a measurement standard or a measurement result is the degree which the measured value is consistent with the $\mathrm{KC} \mathrm{RV}[1,2]$.

To allow the participation in KC of all the NMIs of an RMO, the RMOs may organize their own KC. The RMO $\mathrm{KC}$ must be linked to the corresponding CIPM KC by means of joint NMIs (linking NMIs). This is mandatory to demonstrate global equivalence. Instead of the method to determine of RV, the RMO KC protocol must include the way which the results will be linked to the corresponding CIPM KC RV.

A supplementary comparison ( $\mathrm{SC}$ ) is a comparison, usually carried out by an RMO to meet specific needs not covered by $\mathrm{KC}$ (e.g. regional needs), for instance

^ Correspondence: velychko@hotmail.com measurements of specific artefacts, or measurements of parameters not within the "normal" scope of the Consultative Committees (CC) of CIPM, and for supporting confidence in calibration and measurement certificates of NMIs $[1,3]$.

SCs are normally organized by the RMOs to cover areas or techniques not covered by KCs. Rules for the participation in CIPM and RMO KCs apply to CIPM and RMO SCs also. The differences are next: approval is given by the corresponding RMO committee; degrees of equivalence relative to a SC RV may be computed, but this is not mandatory.

Results of EUROMET.EM-S26 comparison has been linked to the EUROMET.EM-S20 comparison (two SCs). The link is determined from the results of linking NMIs (PTB, Germany and GUM, Poland). GUM did not use the same measurement set-up in both comparisons. Therefore, it was decided to use only the PTB results for link determine [4].

The proposed procedure linking of results of COOMET.EM-S2 comparison [5] to EURAMET.EMK5.1 comparison [6] for electrical power was realized with using results of linking NMIs (SE "Ukrmetrteststandard", Ukraine and BIM, Bulgaria).

\section{Travelling standards for comparisons}

UME (Turkey) was the pilot laboratory in EURAMET. EM-K5.1 KC which would be responsible for providing the travelling standard, coordinating the schedule, collecting and analyzing the comparison data, and preparing of draft reports. 
PTB, the pilot laboratory of the EURAMET.EM-K5 $\mathrm{KC}$ also, was proposed to play a key role in this $\mathrm{KC}$ by taking measurements as much as the number of measurements taken by the pilot laboratory. By this way, the measurement results of PTB would be used to estimate the drift effect of the travelling standard.

The single-phase power converter HEG C1-2 was selected for this KC. The principle of operation is based on time-division-multiplication scheme. The instruments are configured as an $\mathrm{AC}$ power-to-DC voltage transducer with a nominal full-scale DC output of $10 \mathrm{~V}$.

The power converter HEG C1-2 has separated (electrically isolated) voltage and current inputs with the voltage range of $120 \mathrm{~V}$ and the current range of $5 \mathrm{~A}$. The input frequency capability of the instrument is from $45 \mathrm{~Hz}$ to $65 \mathrm{~Hz}$. The internal DC reference voltages (nominally $+7.044 \ldots$. $\mathrm{V}$ and $-7.044 \ldots \mathrm{V}$ ) can be monitored. The nominal fullscale DC output of $10 \mathrm{~V}$ is also available. The nominal fullscale frequency outputs of $10 \mathrm{~Hz}$ and $10 \mathrm{kHz}$ are available with special connectors [6].

The COOMET.EM-S2 SC is the comparison of national standards of electrical power and power factor between the countries - participants of the RMO COOMET. In this comparison took part three NMIs: SE "Ukrmetrteststandard" (UMTS), BIM (from EURAMET also) and BelGIM (Belarus). The UMTS was pilot laboratory which is responsible for providing travelling standard, coordinating the schedule, collecting and analyzing the comparison data, and preparing of draft reports.

The precision electric power standard Radian Research RM 15-04 was selected for COOMET.EM-S2 SC. The RM 15-04 is the most versatile portable standard available for providing as many as 16 different measurement functions.

The RM 15-04 is capable for measuring electrical active power $(\mathrm{Wh} / \mathrm{kW})$. In this $\mathrm{SC}$ was measured electrical active power so it had to be selected kiloWatt $(\mathrm{kW})$ and the constant of the frequency output is 100000000 pulse/kWs. The measure process of measuring electrical active power is fully automatically with the help of connector output count number of pulses which is directly proportional to the measured active power. The output frequency of RM $15-04$ is 50000 pulse/s [5].

The RM 15-04 is well-suited for test applications when require multiple measurements with high accuracy and stability. The RM 15-04 has features three summing current inputs in addition to its auto ranging capabilities which can be used to perform closed link testing. A test current of 150 amps maximum can be used by applying 50 amps to each of the inputs. All errors are in percent of reading at any combination of the normal operating conditions.

The input signals for EURAMET.EM-K5.1 and COOMET.EM-S2 comparisons are shown in Table 1.

\section{Proposed linking procedure}

The procedure used for RMO KC data evaluation is intended to provide linking to CIPM KC data with low uncertainty $[7,8]$.
Table 1. Input signals.

\begin{tabular}{ccc}
\hline Comparison & EURAMET.EM-K5.1 & COOMET.EM-S2 \\
\hline Quantity & HEG C1-2 & RM 15-04 \\
Voltage & $120 \mathrm{~V}$ & $120 \mathrm{~V}$ \\
Current & $5 \mathrm{~A}$ & $5 \mathrm{~A}$ \\
Power factor & $1.0 ; 0,5 \mathrm{Lag} ; 0,5$ Lead; & $1.0 ; 0,5 \mathrm{Lag} ;$ \\
Frequency & $0.0 \mathrm{Lag} ; 0.0$ Lead & $0,5 \mathrm{Lead}$ \\
& $53 \mathrm{~Hz}$ & 50 and $53 \mathrm{~Hz}$ \\
\hline
\end{tabular}

The RMO SCs are carried out with the purpose of confirming calibration and measurement capabilities (CMC) of the corresponding NMI. During the evaluation of the SCs data the measurement uncertainties claimed by the participants of comparisons are confirmed that, essentially, is the confirmation of corresponding measurement CMC $[8,9]$.

Results of COOMET.EM-S2 comparison is to be linked to the EUROMET.EM-K5.1 comparison (SC to the $\mathrm{KC}$ ). BIM did not use the same measurement setup in both comparisons. Therefore, it was decided to use only the UMTS results to determine the link. RVs and its uncertainties are given in Table 2.

The degree of equivalence $D_{i}$ of national standards and its expanded uncertainty $U\left(D_{i}\right)$ that participated in EURAMET.EM-K5.1 [6] and COOMET.EM-S2 [5] comparisons are shown in Table 3, Figures 1 and 2 for $53 \mathrm{~Hz}$.

For each of the joint participants in both comparisons was calculated degree of equivalence and it uncertainty with used next formula:

$$
\begin{aligned}
D_{i} & =x_{i}-R V_{j}, \\
u\left(D_{i}\right) & =\sqrt{u^{2}\left(x_{i}\right)+u^{2}\left(R V_{j}\right)-2 r_{i} u\left(x_{i}\right) u\left(R V_{j}\right)},
\end{aligned}
$$

where $x_{i}$ is measured value for participant;

$\mathrm{RV}_{j}$ is reference value of comparison (for $\mathrm{PF}=1.0 ; 0.5$ Lag; 0.5 Lead);

$r_{i} \quad$ is correlation between the results from the participant and the $R V_{j}$;

$u\left(x_{i}\right)$ is combined standard uncertainty of measured value for NMI;

$u\left(R V_{j}\right)$ is combined standard uncertainty of $R V_{j}$.

If correlations have been ignored $\left(r_{i}=0\right)$

$$
u\left(D_{i}\right)=\sqrt{u^{2}\left(x_{i}\right)+u^{2}\left(R V_{j}\right)} .
$$

Values of $E_{n}$ criterion was determinates

$$
E_{n}=\left|D_{i}\right| / u\left(D_{i}\right) .
$$

According to the recommendation COOMET $\mathrm{R} / \mathrm{GM} / 19$ [9] on the basis of measurement results and associated uncertainties $\left\{x_{i}, u\left(x_{i}\right)\right\}, i=1, \ldots, n$ presented by participants of comparison, calculate the value of the criterion $\chi^{2}$

$$
\chi^{2}=\sum_{i=1}^{n} \frac{\left(x_{i}-\bar{x}_{r e f}\right)^{2}}{u^{2}\left(x_{i}\right)}
$$


Table 2. Reference values and its uncertainties.

\begin{tabular}{cccc}
\hline \multirow{2}{*}{ Comparison } & $\begin{array}{c}\text { Power factor } \\
\mathrm{PF}\end{array}$ & $\begin{array}{c}\text { Reference value } \\
\mathrm{RV} \mu \mathrm{W} /(\mathrm{VA})\end{array}$ & $\begin{array}{c}\text { Uncertainties of RV } \\
\mathrm{u}(\mathrm{RV}) \mu \mathrm{W} /(\mathrm{VA})\end{array}$ \\
\hline \multirow{3}{*}{ EURAMET.EM-K5.1 } & 1.0 & -1.5 & 3.0 \\
& $0.5 \mathrm{Lead}$ & -0.5 & 3.2 \\
& $0.5 \mathrm{Lag}$ & 0.0 & 3.2 \\
\hline \multirow{3}{*}{ COOMET.EM-S2 } & 1.0 & 2.8 & 6.5 \\
& $0.5 \mathrm{Lead}$ & -62.2 & 11.1 \\
& $0.5 \mathrm{Lag}$ & 54.4 & 11.0 \\
\hline
\end{tabular}

Table 3. Degrees of equivalence and its uncertainties $(53 \mathrm{~Hz})$.

\begin{tabular}{ccccc}
\hline \multirow{2}{*}{ Laboratory } & $\begin{array}{c}D_{i} \\
\mu \mathrm{W} /(\mathrm{VA})\end{array}$ & $\begin{array}{c}U\left(D_{i}\right) \\
\mu \mathrm{W} /(\mathrm{VA})\end{array}$ & $\begin{array}{c}E_{n} \\
\text { factor PF }\end{array}$ & Power \\
\hline \multicolumn{5}{c}{ EURAMET.EM-K5.1 } \\
\hline UMTS & 18.2 & 30.6 & 0.5948 & \multirow{2}{*}{ PF 1.0 } \\
BIM & -13.5 & 72.4 & 0.1865 & \\
UMTS & 64.7 & 92.0 & 0.7033 & PF 0.5 Lag \\
BIM & -13.8 & 98.1 & 0.1407 & \\
UMTS & -47.4 & 92.1 & 0.5147 & PF 0.5 Lead \\
BIM & 9.1 & 94.1 & 0.0967 & \\
\hline & \multicolumn{5}{c}{ COOMET.EM-S2 } \\
\hline UMTS & -0.4 & 17.2 & 0.0233 & \\
BIM & -1.1 & 9.8 & 0.1118 & \\
BelGIM & 17.2 & 28.7 & 0.5984 & \multirow{2}{*}{ PF 0.5 Lag } \\
UMTS & 22.1 & 46.3 & 0.4768 & \\
BIM & -2.8 & 16.2 & 0.1731 & \\
BelGIM & 31.1 & 59.1 & 0.5266 & \\
UMTS & -7.4 & 46.9 & 0.1578 & \\
BIM & 1.9 & 15.9 & 0.1194 & \\
BelGIM & -35.4 & 59.0 & 0.5997 & \\
\hline
\end{tabular}

EURAMET.EM-K5.1 - Power at $53 \mathrm{~Hz}$ Degrees of equilence $\left[D_{i}\right.$ and its expanded uncertainty $\left.(k=2), U_{i}\right]$

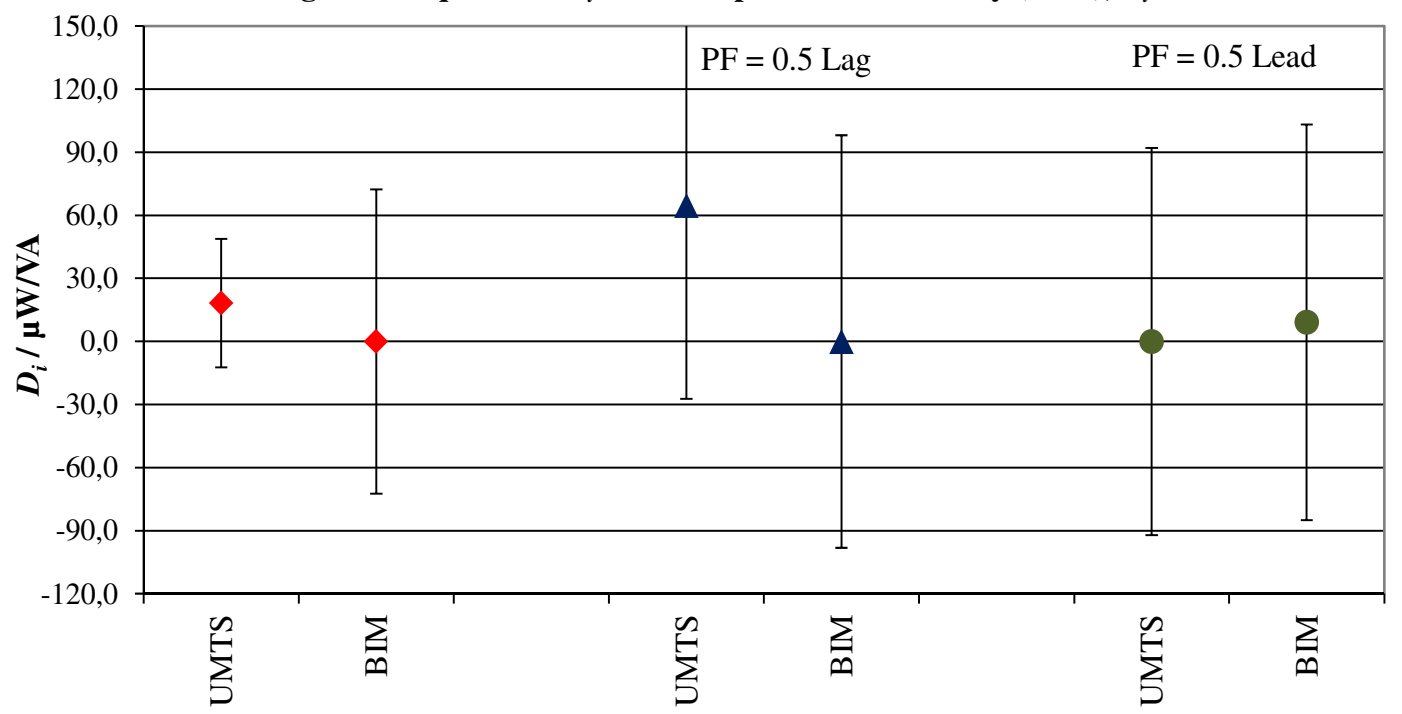

Fig. 1. Degrees of equivalence for participants of EUROMET.EM-K5.1 for power factors 1.0, 0.5 Lag and 0.5 Lead. 
COOMET.EM-S2 - Power at $53 \mathrm{~Hz}$ Degrees of equilence $\left[D_{i}\right.$ and its expanded uncertainty $\left.(k=2), U_{i}\right]$

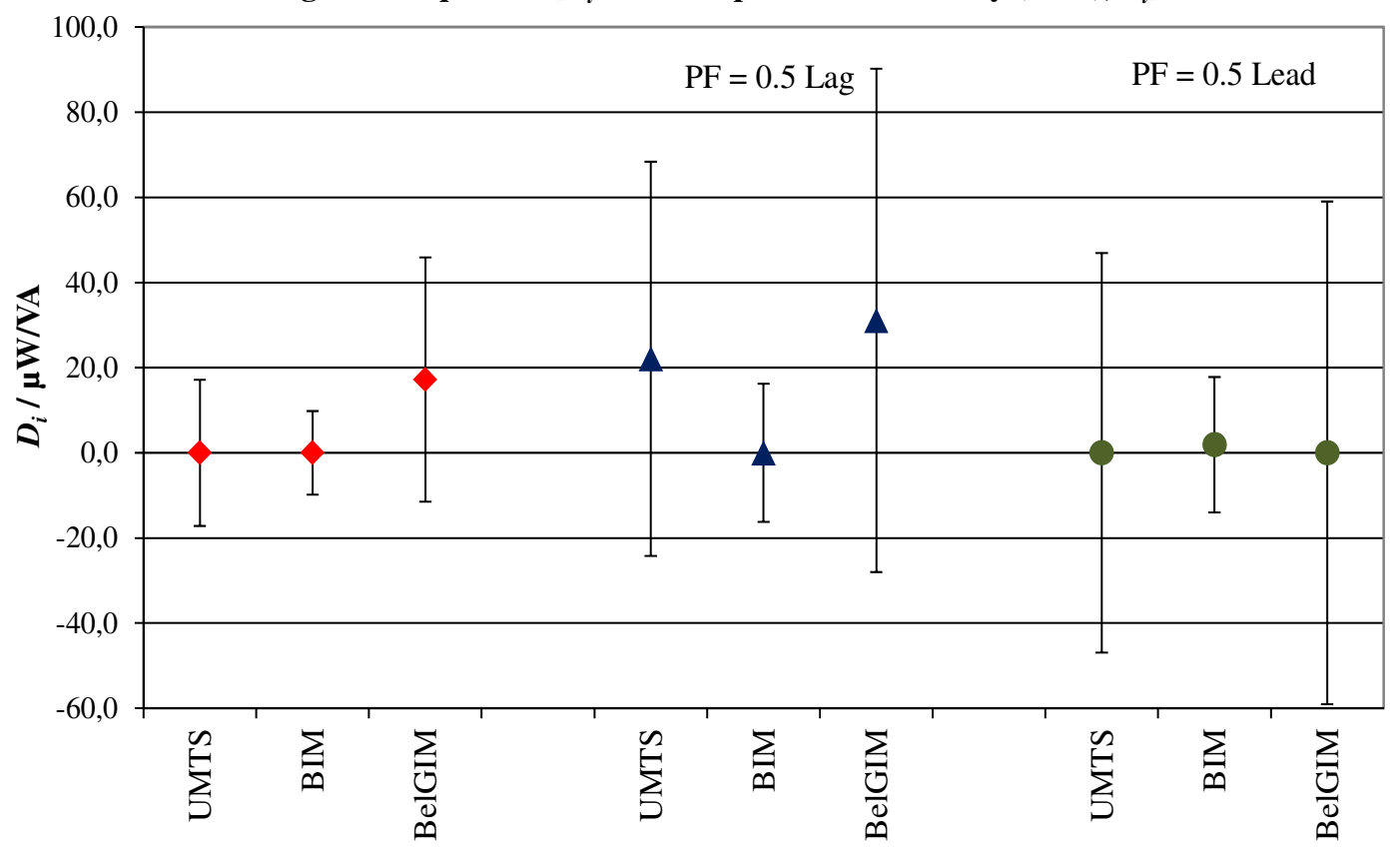

Fig. 2. Degrees of equivalence for participants of COOMET. EM-S2 for power factors 1.0, 0.5 Lag and 0.5 Lead.

Table 4. Values of criterion $\chi^{2}$ for COOMET.EM-S2 $(53 \mathrm{~Hz})$.

\begin{tabular}{ccc}
\hline Power factor & $\chi^{2}$ & $\chi_{0,95}^{2}(n-1)$ \\
\hline PF & & \\
\hline $.0(53 \mathrm{~Hz})$ & 0.4001 & \\
$0.5 \mathrm{Lag}(53 \mathrm{~Hz})$ & 0.5850 & 5.9915 \\
$0.5 \mathrm{Lead}(53 \mathrm{~Hz})$ & 0.4261 & \\
\hline
\end{tabular}

where $\bar{x}_{r e f}$ is SC RV and $u^{2}\left(\bar{x}_{r e f}\right)$ is the uncertainty of the RV.

To checks consistency of comparisons were used criterion value, calculated from data provided by the NMI does not exceed the critical value $\chi^{2}$ for confidence level 0.95 and the number of degrees of freedom $n-1$

$$
\chi^{2} \prec \chi_{0,95}^{2}(n-1) .
$$

Values for criterion $\chi^{2}$ for COOMET.EM-S2 are given in Table 4.

The results of the COOMET.EM-S2 comparison are to be expressed in relation to the EURAMET.EM-K5.1 $R V-R V_{K 5.1}$. For this purpose the degrees of equivalence of COOMET.EM-S2 comparison (indicated $D_{\mathrm{S} 2}$ ), will be corrected by a correction $d$, which is determined from the results of the participant NMI in both comparisons (UMTS):

$$
d=D_{\mathrm{K} 5.1 \mathrm{UMTS}}-D_{\mathrm{S} 2 \mathrm{UMTS}},
$$

where

$D_{\text {K5.1UMTS }}$ is degree of equivalence of national standard UMTS in EURAMET.EM-K5.1 comparison;
$D_{\text {S2UMTS }}$ is degree of equivalence of national standard UMTS in COOMET.EM-S2 comparison. with the uncertainty:

$$
u(d)=\sqrt{u^{2}\left(D_{\mathrm{K} 5.1 \mathrm{UMTS}}\right)+u^{2}\left(D_{\mathrm{S} 2 \mathrm{UMTS}}\right)} .
$$

UMTS degrees of equivalence, correction $d$ and its uncertainties are shown in Table 5.

The corrected degrees of equivalence for the participants in COOMET.EM-S2 in terms of $R V_{K 5.1}$ are then given by:

$$
D_{\mathrm{S} 2 i}^{\prime}=D_{\mathrm{S} 2 i}+d
$$

with the uncertainty:

$$
u^{\prime}\left(D_{\mathrm{S} 2 i}\right)=\sqrt{u^{2}\left(D_{\mathrm{S} 2 i}\right)+u^{2}(d)} .
$$

\section{Practical linked results}

The degrees of equivalence for participants of COOMET.EM-S2, and corrected degrees of equivalence for BelGIM in terms of $R V_{K 5.1}$ with using formulas (9) and (10) are shown on Table 6 and Figure 3 (*EURAMET.EM-K5.1; **COOMET.EM-S2).

Results of BelGIM are linked to the EUROMET.EMK5.1 comparison with using proposed procedure. The link is determined from the results of linking NMIs. BIM did not use the same measurement set-up in EUROMET.EMK5.1 and COOMET.EM-S2 comparisons. Therefore, it was decided to use only the UMTC results to determine the link. 
Table 5. Degrees of equivalence, correction factor and its uncertainties for UMTS $(53 \mathrm{~Hz})$.

\begin{tabular}{|c|c|c|c|c|c|}
\hline $\begin{array}{c}D_{\text {K5.1UMTS }} \\
\mu \mathrm{W} /(\mathrm{VA})\end{array}$ & $\begin{array}{c}U\left(D_{\mathrm{K} 5.1 \mathrm{UMTS}}\right) \\
\mu \mathrm{W} /(\mathrm{VA})\end{array}$ & $\begin{array}{c}D_{\text {S2UMTS }} \\
\mu \mathrm{W} /(\mathrm{VA})\end{array}$ & $\begin{array}{c}U\left(D_{\text {S2UMTS }}\right) \\
\mu \mathrm{W} /(\mathrm{VA})\end{array}$ & $d$ & $U(d)$ \\
\hline & & PF 1.0 & & & \\
\hline 18.2 & 30.6 & $\begin{array}{c}-0.4 \\
\text { PF } 0.5 \text { Lag }\end{array}$ & 17.2 & 18.6 & 25.3 \\
\hline 64.7 & 92.0 & $\begin{array}{l}22.1 \\
\text { PF } 0.5 \text { Lead }\end{array}$ & 46.3 & 42.6 & 79.5 \\
\hline-47.4 & 92.1 & -7.4 & 46.9 & -40.0 & 79.3 \\
\hline
\end{tabular}

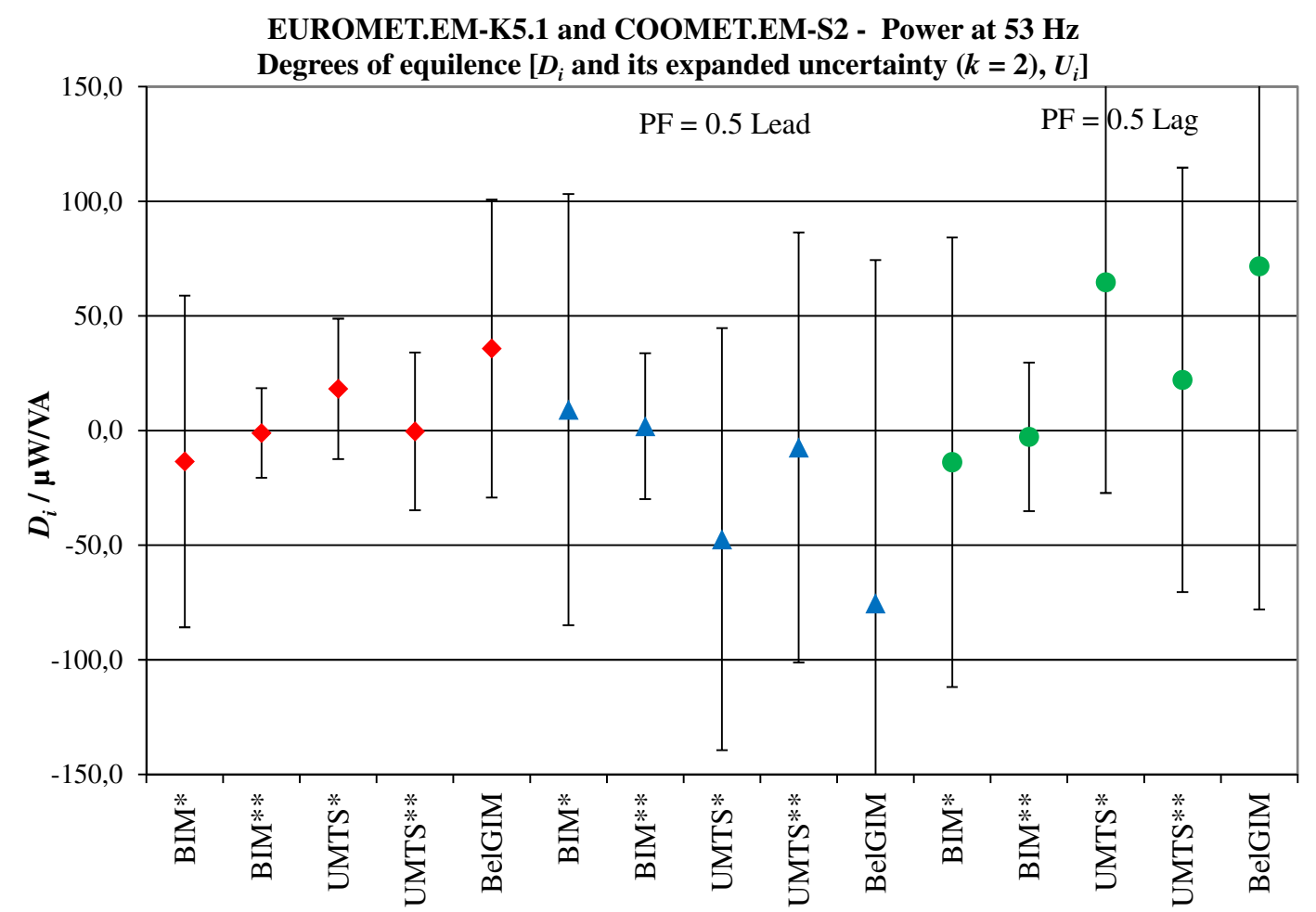

Fig. 3. Degrees of equivalence for participants of COOMET.EM-S2, and corrected degrees of equivalence for BelGIM in terms of $R V_{K 5.1}$

Table 6. Degrees of equivalence participants and it's uncertainties for COOMET.EM-S2 in terms RV EURAMET.EM-K5.1 (53 Hz).

\begin{tabular}{cccc}
\hline Laboratory & $\begin{array}{c}D_{i} \\
\mu \mathrm{W} /(\mathrm{VA})\end{array}$ & $\begin{array}{c}U\left(D_{i}\right) \\
\mu \mathrm{W} /(\mathrm{VA})\end{array}$ & $\begin{array}{c}\text { Power factor } \\
\mathrm{PF}\end{array}$ \\
\hline UMTS & 18.2 & 30.6 & \\
BIM & -13.5 & 72.4 & PF 1.0 \\
BelGIM & 35.8 & 65.05 & \\
UMTS & 64.7 & 92.0 & \\
BIM & -13.8 & 98.1 & PF 0.5 Lag \\
BelGIM & -75.4 & 149.69 & \\
UMTS & -47.4 & 92.1 & \\
BIM & 9.1 & 94.1 & PF 0.5 Lead \\
BelGIM & 71.7 & 149.78 & \\
\hline For BelGIM are corrected degrees of equivalence \\
\hline
\end{tabular}

The corrected results BelGIM in COOMET.EM-S2 comparison can be compared to the results of the
CCEM-K4, EUROMET.EM-K5, EUROMET.EM-K5 and SIM.EM-K5 comparisons which shown on Figures 4-6 for power factors 1.0; 0.5 Lag; 0.5 Lead on $53 \mathrm{~Hz}[10,11]$.

\section{Conclusion}

The results of a regional key comparison EURAMET.EMK5.1 and a supplementary comparison COOMET.EM-S2 for electrical power showed good agreement between all but one of the participating laboratories.

The results of RMO SCs for confirming CMCs NMIs are used. For each of the joint participants in key and supplementary comparisons for equal nominal of electrical quantity can be calculated degrees of equivalence national standards and it uncertainty in term KC RV.

The procedure of practical linking the results of key and supplementary comparisons of RMOs for electrical power for power factors 1.0; $0.5 \mathrm{Lag}$; 0.5 Lead on $53 \mathrm{~Hz}$ are proposed. 


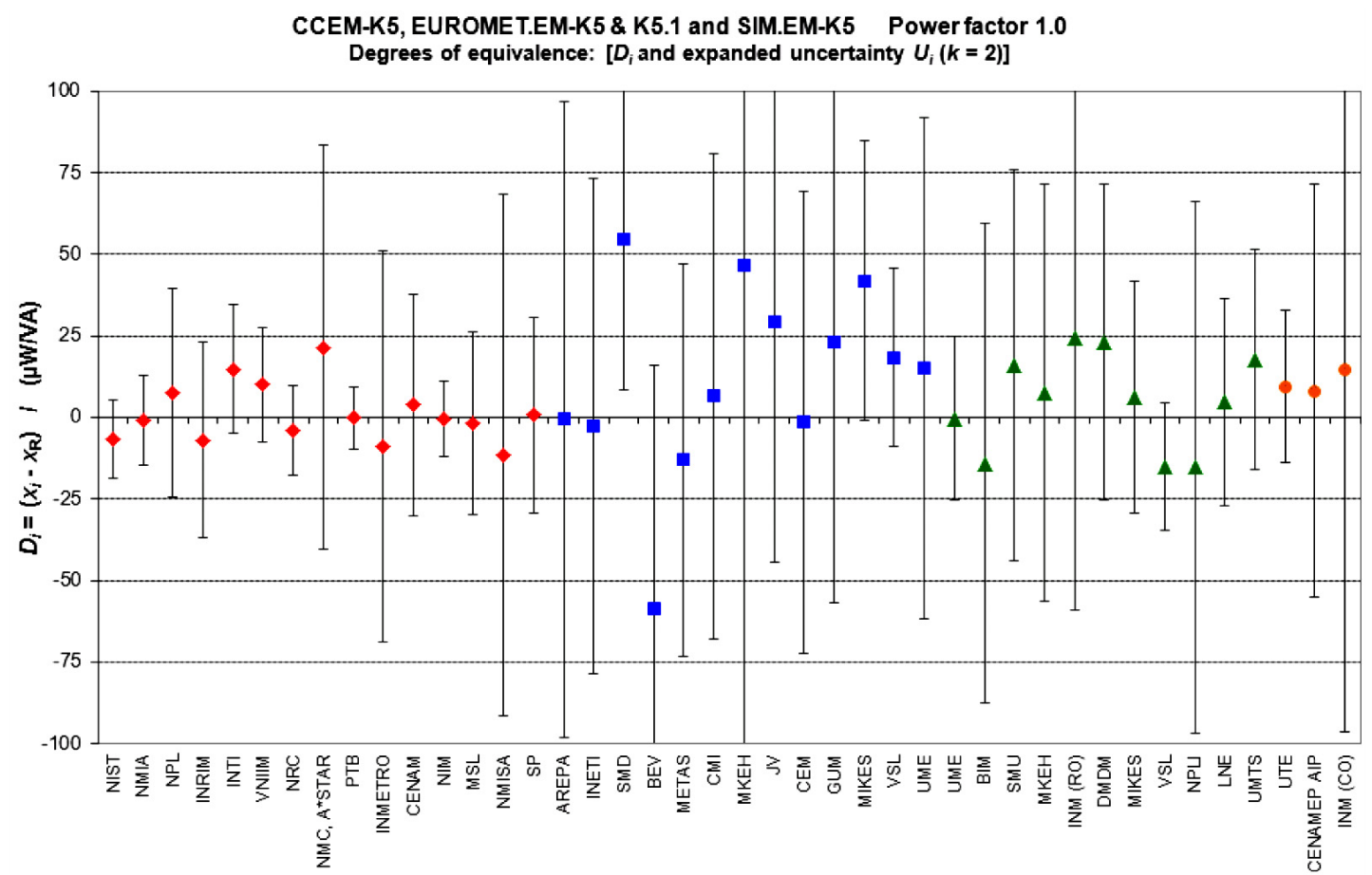

Red diamonds: participants in CCEM-K5

Blue squares: participants in EUROMET.EM-K5 only $\quad U_{\text {MKEH }}=172 \mu \mathrm{W} / \mathrm{VA}$

Green triangles: participants in EUROMET.EM-K5.1 only

Orange circles: participants in SIM.EM-K5 only

Fig. 4. Degrees of equivalence for participants of CCEM-K5, EUROMET.EM-K5, EUROMET.EM-K5.1 and SIM.EM-K5 for $\mathrm{PF}=1.0$.

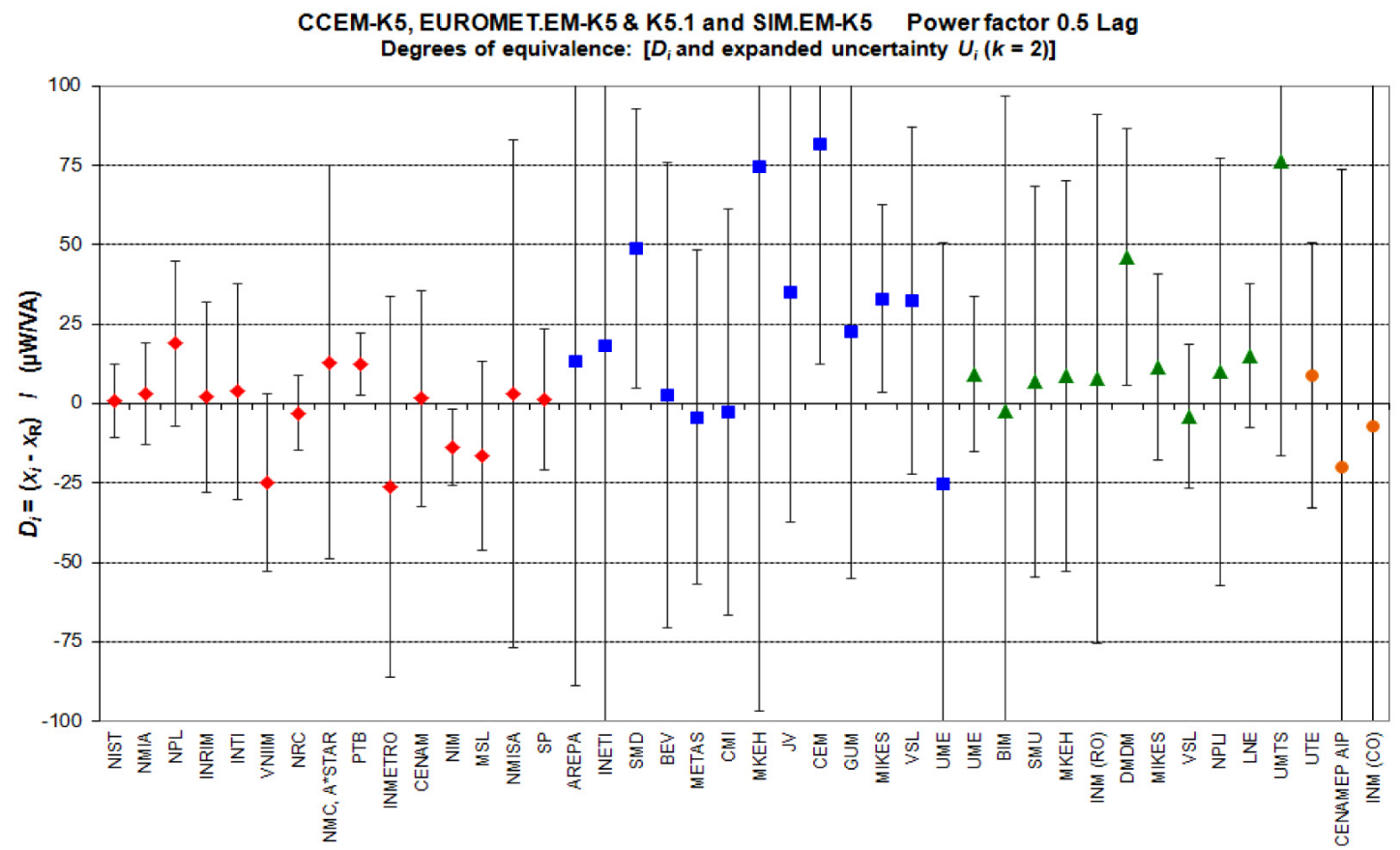

Red diamonds: participants in CCEM-K5

Blue squares: participants in EUROMET.EM-K5 only $\quad U_{\text {INETI }}=195 \mu \mathrm{W} / \mathrm{VA}$

Green triangles: participants in EUROMET.EM-K5.1 only $\quad U_{\mathrm{INM} / \mathrm{CO}]}=132 \mu \mathrm{W} / \mathrm{V} / \mathrm{A}$

Orange circles: participants in SIM.EM-K5 only

Fig. 5. Degrees of equivalence for participants of CCEM-K5, EUROMET.EM-K5, EUROMET.EM-K5.1 and SIM.EM-K5 for $\mathrm{PF}=0.5$ Lag. 


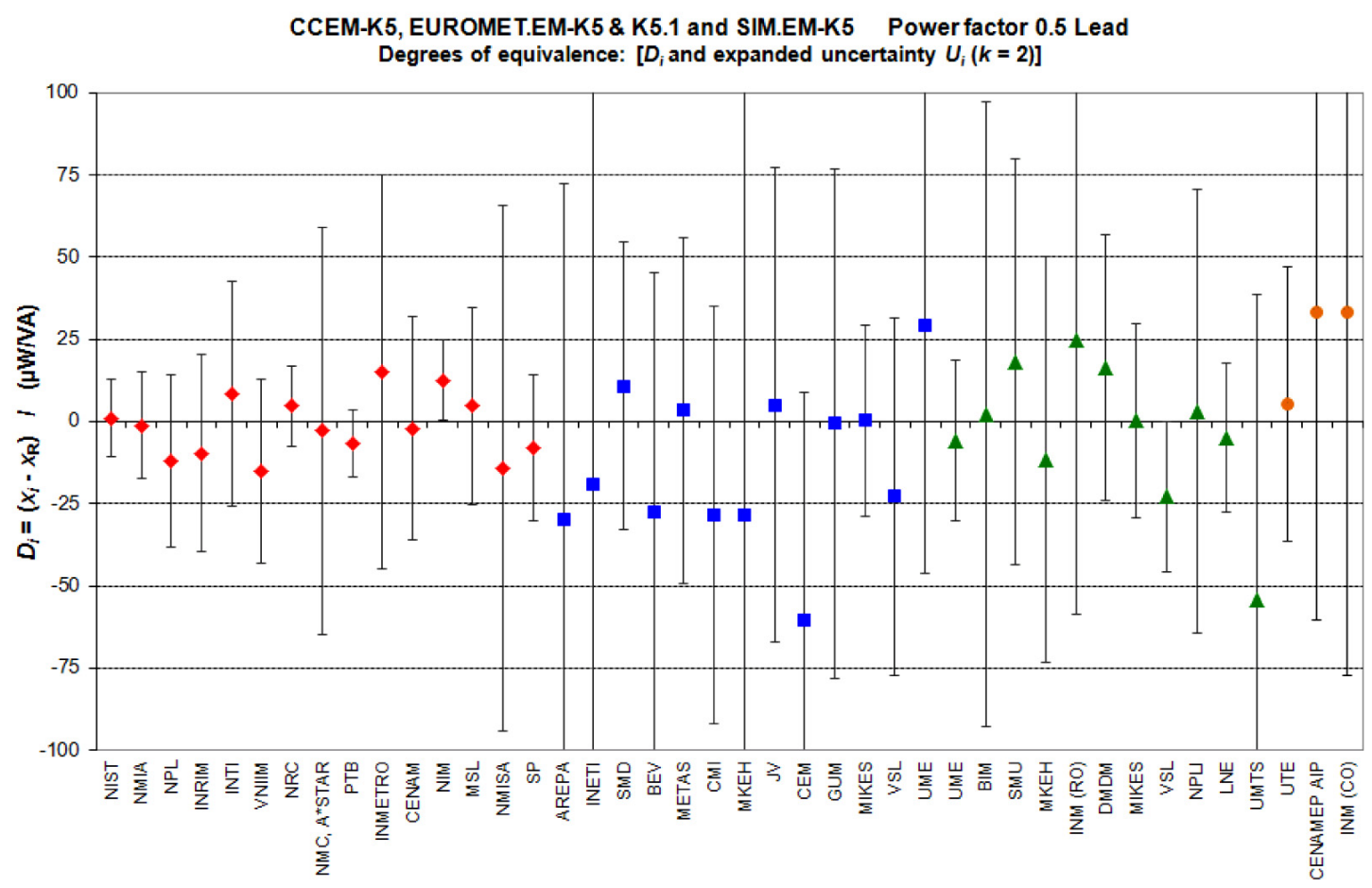

Red diamonds: participants in CCEM-K5

Blue squares: participants in EUROMET.EM-K5 only

Green triangles: participants in EUROMET.EM-K5.1 only

$U_{\text {INETI }}=152 \mu \mathrm{W} / \mathrm{NA} \quad U_{\text {MKEH }}=171 \mu \mathrm{W} / \mathrm{NA}$

Orange circles: participants in SIM.EM-K5 only

Fig. 6. Degrees of equivalence for participants of CCEM-K5, EUROMET.EM-K5, EUROMET.EM-K5.1 and SIM.EM-K5 for $\mathrm{PF}=0.5$ Lead.

\section{References}

1. CIPM MRA-D-05, Measurement comparisons in the context of the CIPM MRA

2. O.N. Velichko, Traceability of measurement results at different levels of metrological work. Measurement Techniques 52, 1242-1248 (2009)

3. O.N. Velichko, Calibration and measurement capabilities of metrological institutes: features of preparation, examination, and publication, Measurement Techniques 53, $721-726(2010)$

4. E. Dierikx, A. Nestor, J. Melcher, A. Kölling, L. Callegaro, EURAMET.EM-S26 Supplementary Comparison Inductance measurements of $100 \mathrm{mH}$ at $1 \mathrm{kHz}$, EURAMET project 816, Final Report, December 2011, VSL, Dutch Metrology Institute

5. O. Velychko, S. Karpenko, V. Gachok, O. Akhmadov, COOMET.EM-S2 Supplementary Comparison of $50 / 60 \mathrm{~Hz}$ Power, Final Report, Febr. 2013, SE "Ukrmetrteststandard"
6. H. Çaycı, EURAMET.EM-K5.1 Key Comparison of $50 / 60 \mathrm{~Hz}$ Power, Final Report, March 2011, TÜB_TAK Ulusal Metroloji Enstitüsü

7. R/GM/14:2006, Guidelines for data evaluation of COOMET key comparison

8. O. Velychko, T. Gordiyenko The estimation of the measurement results with using statistical methods. J. Phys. Conf. Ser., IOP Publication 588, 012017 (2015)

9. R/GM/19:2008, Guideline on COOMET supplementary comparison evaluation

10. O. Velychko, S. Karpenko, V. Gachok, The Results of supplementary comparison of 50/60 Hz Power COOMET.EM$\mathrm{S} 2$, in 10th International Congress on Electrical Metrology, Congress Digest, Buenos Aires, Argentina (September 2527, 2013), 4 p.

11. www.kcdb.bipm.org. KCDB BIPM. 